\title{
A Collaborative Research Exploration of Pollutant Mixtures and Adverse Birth Outcomes by Using Innovative Spatial Data Mining Methods: The DoMiNO Project
}

\author{
Osnat Wine $^{1,+}{ }^{(}$, Osmar R. Zaiane ${ }^{2,+}$ and Alvaro R. Osornio Vargas ${ }^{1, *,+}+(\mathbb{D}$ \\ 1 Department of Pediatrics, University of Alberta, Edmonton, AB T6G 1C9, Canada; osnat@ualberta.ca \\ 2 Department of Computing Science, University of Alberta, Edmonton, AB T6G 2E8, Canada; \\ zaiane@cs.ualberta.ca \\ * Correspondence: osornio@ualberta.ca; Tel.: +1-780-492-7092 \\ + On behalf of the DoMiNO Project Team, Data Mining and Neonatal Outcomes (DoMiNO), University of \\ Alberta, Edmonton, AB T6G 1C9, Canada.
}

Received: 13 December 2018; Accepted: 18 March 2019; Published: 25 March 2019

check for updates

\begin{abstract}
Environmental health research is gaining interest due to the global concern of environmental factors impacting health. This research is often multifaceted and becomes complex when trying to understand the participation of multiple environmental variables. It requires the combination of innovative research methods, as well as the collaboration of diverse disciplines in the research process. The application of collaborative approaches is often challenging for interdisciplinary teams, and much can be learned from in-depth observation of such processes. We share here a case report describing initial observations and reflections on the collaborative research process of the Data Mining and Neonatal Outcomes (DoMiNO) project (2013-2018), which aimed to explore associations between mixtures of air pollutants and other environmental variables with adverse birth outcomes by using an innovative data mining approach. The project was built on interdisciplinary and user knowledge participation with embedded evaluation framework of its collaborative process. We describe the collaborative process, the benefits and challenges encountered, and provide insights from our experience. We identified that interdisciplinary research requires time and investment in building relationships, continuous learning, and engagement to build bridges between disciplines towards co-production, discovery, and knowledge translation. Learning from interdisciplinary collaborative research experiences can facilitate future research in the challenging field of environmental health.
\end{abstract}

Keywords: spatial data mining; adverse birth outcomes; interdisciplinary research; integrated knowledge translation; collaboration; environmental health research; exposome

\section{Introduction}

Environmental risk factors such as air pollution [1] contribute to the burden of disease in children worldwide, driving a growing interest and need in children's Environmental Health (EH) research. This research field is complex, as there is the need to study multiple types of environmental exposures, various groups of variables for each type of exposure, and several windows of vulnerability (e.g., in utero development, post-natal) in order to understand the role of the exposome in the health of people and the planet [2].

An example of the potential environmental impact on health is adverse birth outcomes (ABO). $\mathrm{ABO}$, such as low birth weight and preterm birth, are significant public health concerns. ABO represent a multi-factorial set of conditions that result in significant, immediate, and long-term health 
consequences [3,4]. Moreover, $\mathrm{ABO}$ are increasing problems worldwide as more than 1 in 10 babies is born prematurely $[5,6]$.

Current research identifies associations between $\mathrm{ABO}$ and various determinants of health, which include social factors such as poverty and stress; biological factors such as diabetes, infection and maternal age; and environmental pollutants including metals, $\mathrm{PM}_{10}$ and $\mathrm{SO}_{2}$ [7-9]. Past research commonly disregarded the combined effects and interaction among multiple environmental stressors mainly due to methodological limitations at the monitoring and analytical level.

Research studies, mainly focusing on monitored urban pollutants, have identified linkages between environmental exposures, and fetal and early childhood deleterious effects, along with genetic, physical, social, dietary and biological factors [10]. However, the contribution of industrial pollution has not been fully explored [11], even though some of those chemicals are known to be developmental toxicants. This knowledge gap is even broader when assessing the role of mixtures of chemicals. In that respect, there is strong evidence that low-level exposure to multiple, similar-acting, but potentially distinct chemicals demonstrate dose additive mixture effects [12]. Researchers and funding agencies are calling for the development of new methods, which will explore mixtures that impact human health and different ecosystems [13] in order to advance research on links between environmental pollutants and $\mathrm{ABO}$.

Furthermore, the possible association and influence of multiple environmental factors on $A B O$ must be understood within a geospatial context of co-location, after considering maternal confounders. The complexity of these data requires analytical tools that go beyond conventional statistical and geographical approaches, such as data mining. Data mining (DM) is used in the domain of health sciences for hypothesis development and to explore early diagnosis and prevention of diseases [14]. The spatial aspect of DM is also used in health science applications such as detection of epidemics and pandemics $[15,16]$. However, the use of advanced spatial DM for the evaluation of complex geospatial relations between environmental factors (e.g., exposome) and different health outcomes is still in early stages and has good potential for future application in the research on air pollution [17]. Considering that this type of research has a unique, complex and multifaceted context which requires consideration of time and space, there is a need for interdisciplinary and multisectoral engagement [18-21].

Interdisciplinary research refers to a paradigm of knowledge formation, which implies a process of answering a complex question/problem by drawing on different disciplines' methods and perspectives and by integrating their insights, reaching a more comprehensive understanding. The disciplines engaged in the process serve as a means to an end [19]. The goal of interdisciplinary research is integration-assimilating the different insights in order to achieve a holistic understanding to address complex systems [22]. Interdisciplinarity is becoming an integral part of many research projects and as described by the Committee on Facilitating Interdisciplinary Research (USA), this is driven by "the inherent complexity of nature and society, the desire to explore problems and questions that are not confined to a certain discipline, the need to solve societal problems and the power of new technologies" [23].

In the case of environment and health research, interdisciplinarity is both instrumental (problem driven) and critical (society driven) [19] due to its potential to support policies, practice and research [24]. Thus, there is the need for participation of interdisciplinary researchers and stakeholders/knowledge users in a collaborative research process [25], for the creation of knowledge and its translation [21]. These forms of collaborations can address the complexity and uncertain and sensitive outcomes intrinsic to the context of EH research [26]. Due to the unique characteristics of EH research, the application of interdisciplinary collaborative best practices is often challenging, and much can be learned from in-depth observation of real-life experiences.

We present here the DoMiNO research project (Data Mining \& Neonatal Outcomes, 2013-2018) [27], an interdisciplinary research project with knowledge user participation, which investigated co-location of mixtures of environmental pollutants and $\mathrm{ABO}$ by using an innovative spatial data mining approach, an embedded collaborative framework and the inclusion of a dedicated evaluation of the collaborative process. 
DoMiNO's case illustrates the collaborative approach experience in a complex research context of understanding some aspects of the exposome. We describe the project in its unique context and the opportunities for new knowledge discovery when using an innovative research approach of developing new algorithms to account for spatial co-occurrence of environmental factors and ABOs, which was supported by a collaborative approach of experts from different domains. Moreover, we portray the collaborative process, how it benefited the research, and the challenges it created; and share initial insights on the interdisciplinary process based on our experience.

\section{Methods}

We present an EH research case, where we describe its embedded collaborative and interdisciplinary process. We provide a detailed description of the DoMiNO project 'the case', including the research context and framework, the research progress, and outcomes with an emphasis on the collaborative and interdisciplinary approach.

We studied the case at different points in time, aiming to reveal changes in conditions or impacts [28] of team members in the collaborative and interdisciplinary process. Multiple data sources, including meeting minutes and recordings, project logs and field notes, were used to provide the descriptions.

This case report will hopefully provide enough information about lessons learned so that others who are currently involved or plan to engage in similar research can understand what interdisciplinary and collaborative research entails and draw their own conclusions $[29,30]$.

The DoMiNO study received approval from the University of Alberta Health Research Ethics Board Human Panel (Study ID Pro00039545) and institutional approval from the Alberta Perinatal Health Program and Canadian Neonatal Network.

\section{The DoMiNO Project}

\subsection{The Research Framework}

The research objective of the DoMiNO project was to discover co-location of $\mathrm{ABO}$ with specific mixtures of industrial emissions and social factors as a way to provide insights to postulate new hypotheses.

The study focused on the period between 2006 and 2012 and used data from (1) the National Pollution Release Inventory ( $>300$ chemicals annual emissions); (2) maternal variables (21 variables) and birth data $(>300,000$ births) from the Alberta Perinatal Health Program and the Canadian Neonatal Network; (3) wind data; (4) socioeconomic status (SES) index (five categories), and (5) urban air pollution models. These databases were chosen for their public availability (NPRI, Wind) and for their comprehensiveness and reliability (neonatal and maternal data). Other data originated from DoMiNO team members (SES Index, urban air pollution modules).

Due to a large number of variables involved in this complex research and the resulting large number of potential combinations, we developed novel data mining approaches based on geographical location. Newly developed algorithms identified associations between $\mathrm{ABO}$ and mixtures of chemicals occurring at the same location, after considering wind patterns and maternal mobility. Our approach also included a computer-based visualization tool to identify and present results. Furthermore, ad-hoc maps using geographic information systems (GIS) and traditional statistical approaches provided support to the data mining findings and insights into how complementary traditional research approaches supported the generation of co-location hypothesis and the validation of the findings. Altogether, several associations were selected as the potential hypotheses to relate specific mixtures of pollutants with ABO. Figure 1 illustrates the research framework. 


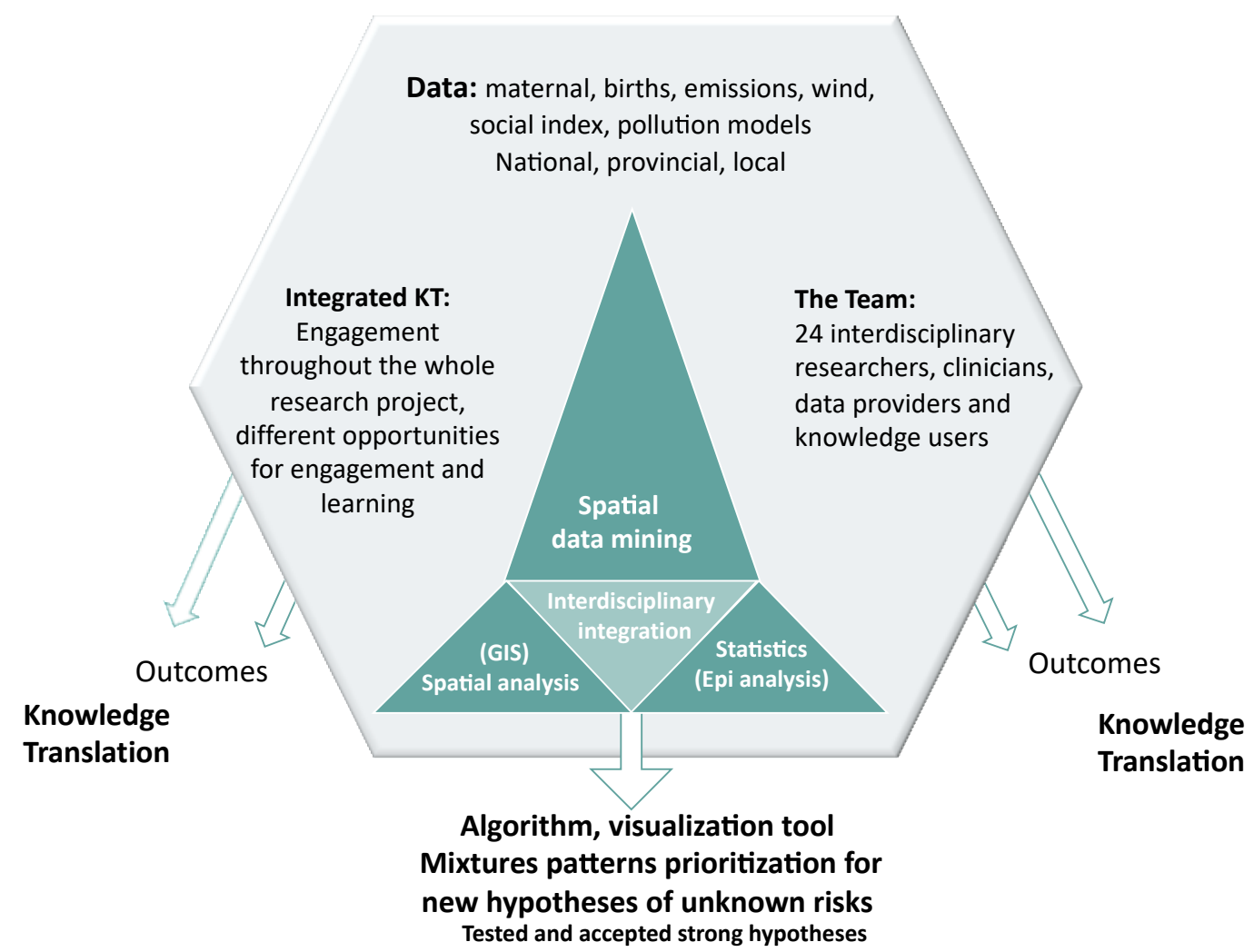

Figure 1. The DoMiNO Project research framework.

\subsection{The Team and Collaborative Approach}

The complexity of the DoMiNO project resides in the EH research context and the various methods employed, requiring individuals with diverse expertise engaging in an interdisciplinary research process that also included a partnership with knowledge users.

The DoMiNO research team consisted of over 20 team members. The team included researchers, clinicians, graduate students, and knowledge users. Research members' expertise included EH \& public health, computing science (data mining), epidemiology, geography, neonatology, obstetrics and gynecology, pediatrics, and knowledge translation (KT). The team also included knowledge users from non-government organizations (NGO), government agencies, which focus on science and policy and data providers. This diverse collective expertise reflects the complexity of the question and the research. Most members of the team resided in one city. The rest of the team was dispersed in different geographical locations and time zones.

Beyond the interdisciplinary methodology, an integrated knowledge translation (iKT) approach based on participatory principles and engaged scholarship [31] was embedded in the research framework. By definition, iKT promotes the participation of knowledge users from the early stages of the project throughout the whole research process, as well as knowledge translation and exchange phases, and take part in knowledge creation and steering of the research to be more relevant to users [32]. All team members were involved in the research process from conception through all the research phases. The team members were engaged in obtaining, analyzing, and interpreting useful information from large sets of data, and developing KT strategies as the project progressed.

The collaborative framework included: (1) A governance structure in the form of a steering committee, whose role was to support project management and decision-making; (2) an engagement plan, which included opportunities to participate in the different phases of the research through annual face-to-face meetings, teleconferences, and email updates; and (3) an embedded evaluation plan, which informed participants of the research undertaking and addressed the needs of the collaboration, as well as enabled scientific learning on the processes of collaboration. The principal investigators 
and research coordinator were responsible for project management and communication and were supported by the steering committee.

\subsection{The DoMiNO Research Process}

\subsubsection{Building the Project}

The first steps of the project involved constructing the research plan, bringing together the team members, designing and writing the proposal, and articulating the project objectives. Once funding was guaranteed, the process focused on obtaining ethics approval and ABO data from local and national sources. These agreements were complex, considering that birth data needed to ensure privacy and confidentiality; therefore, there was need for assurances that no individual identifiers would be compromised since we worked with individuals' postal codes.

An important initial step was to build a baseline from which the team could start working together, since most members did not know each other and were unfamiliar with some of the methods planned for the research. At that time, we conducted individual interviews with all team members about their previous experiences with interdisciplinarity and knowledge user-oriented research and advice for this collaborative research. Through this baseline interview, we explored the potential challenges related to the interdisciplinary practice of the project, and suggestions on how to address those; what the best strategies for communication management are; and what expectations members have regarding the project and suggestions they may have on what to include in the first meeting. Findings from this interview informed project planning, and the results were shared with the whole team in the first meeting, acknowledging the contribution of these baseline interviews to the planning of the meeting. The meeting agenda reflected the suggestions and needs that team members made in the baseline interviews and inspired the following meeting themes as objectives (Annual Meeting 1, Agenda):

- Getting to know the team;

- Clarifying and updating the project;

- Developing a shared team vision.

The team got together for a first kick-off face-to-face meeting (the first of four). For the few who were unable to attend in person, the meeting was selectively broadcasted live for them to join online. The meeting enabled the beginning of building relationships among team members and getting familiarized with the different members' backgrounds and expertise through the development of a shared understanding of the different concepts, which were integral to constructing the project. The meeting offered an opportunity to clarify the project's future route, the objectives and expected outcomes, and preliminary discussion on the desired and appropriate knowledge translation goals. The conversation included clarifications about timelines, expectations, roles, and responsibilities. A discussion on communication management also took place to clarify the best strategies for this team, after the baseline interviews presented mixed responses and thus a realization that "... the project would need multi-prong communication approach" (Annual Meeting 1, Minutes), which will include emails, a website as a repository, newsletters, individual or sub-team discussions with experts as required.

In response to comments made during this meeting and the baseline interviews, specific individual discussions followed to further clarify the project boundaries of what the project will and will not include, establish the research framework, and clarify roles. The steering committee for DoMiNO was formed and took part in planning and decision making of the entire research process through monthly or bimonthly teleconferences.

\subsubsection{Constructing the Building Blocks for the Research}

Once data were available, the entire team met in person for a progress report and for a workshop to plan and design the research path, which was necessary for the DM process. Content experts decided on inclusion and exclusion criteria for the different variables used to conduct the research and 
the level of investigation (e.g., geographic areas for the different variables). Once this plan was clarified, members of the team, the principal investigators, and students from different disciplines continued in cleaning and harmonizing the data according to the protocol developed with the assistance of specialists in the team, for the subsequent research processes.

Research activities focused then on developing data exploration approaches based on the three research methods: spatial DM, statistics and GIS. Graduate students were mainly engaged in this phase alongside consulting with content experts as needed. The DM team developed a unique, new and efficient algorithm to discover contrastive motifs [33] and created a list of association patterns. Concurrently, statistics and GIS, explored urban and rural differences in ABO occurrence. Different maps were developed to identify the geographic distribution of $\mathrm{ABO}$, pollutants and socioeconomic status indices [34], that later served to complement and finalize the analysis. These processes created a preliminary list of colocation patterns when brought together.

Throughout this period, rapport with the whole team was kept using newsletters and emails in which progress was shared. We also initiated, based on team members' suggestions, webinar sessions, which served as learning opportunities and enabled discussion with the entire team on results, future steps and follow up with individual or sub-team discussions as required. Through these activities, the research progressed.

The team also engaged in reflective discussions and identified difficulties resulting from the interdisciplinary nature of the project, such as different perspectives and vocabularies. In order to address those issues, all future interactions contemplated 'building bridges' between disciplines and getting familiarized with each other's terminologies and meanings. Several different strategies were applied, including continuous learning opportunities, repetition of concepts, methods and terms. Additionally, a lexicon that included important terms, methods descriptions, data sources, among others, was shared among all team members. Over time, the team became familiar with the different methods and terminologies used, as was stated by team members 'understanding the different terminologies is getting better... ' (Annual Meeting 3, Minutes) and found the lexicon to be helpful 'we have to have a good understanding of all measures and better understanding of the data: the glossary [lexicon] is nice!' (Annual Meeting 4, Minutes) so they were able to be meaningfully engaged in the research process.

\subsubsection{Refining Results}

Once the first association patterns were identified, with the guidance of the data mining team members, the team jointly supported the design of a visualization tool (VizAR) for identifying data mining patterns $[35,36]$. By using this visualization tool, findings were easily presented according to the different pollutants, the birth outcomes, and the location where they co-occur.

Team members took part in several face-to-face workshops, webinars and surveys to first learn about the tool and then brainstorm to provide input regarding issues related to the inclusion of data, design, processes used, prioritization methods, and usability of the tool. This process helped in shaping the tool itself with new types of analysis and functionalities. As was described by the DM team, 'many versions of the tool were produced so far in response to the team comments and feedback' (Annual Meeting 4, Minutes). Through this iterative process and the joint interdisciplinary effort, the outcome resulted in an interactive tool that enabled users, team members, and external users to explore the different patterns according to their parameters of interest, such as specific chemicals, locations, or birth outcomes. This visualization tool enabled exploration, sorting, prioritizing, and identification of mixtures with strong data mining associations with $\mathrm{ABO}$ to generate new hypotheses.

\subsubsection{Prioritization, Interpretation and Validation of Results}

The last stage was to identify new hypotheses based on the data mining findings. Using the visualization tool (VizAR), the whole team met to discuss, interpret, decide on new hypotheses, identify other project outcomes, and develop a knowledge translation plan. 
The expectation was that the team would identify patterns using VizAR to generate hypotheses, as was expressed in the beginning of the meeting by the Principal Investigator: "... We are making discovery, not causality ... VizAR is like a microscope; the microscope cannot interpret the results ... we used different methods to rate the patterns; there is no methodology to tell us which is the best way to sort" (Annual Meeting 4, Minutes).

Coming from different disciplines and epistemologies, members had different perspectives on outcomes selection and the ways to claim validity and reproducibility of the results in this discovery-based research. This situation created a challenging discussion for finalizing the results. It was difficult to make a joint decision about which patterns could be considered as strong hypotheses, and which measures could determine what 'strong' meant. Based on the different perspectives in the team, various suggestions were made to move the project forward, such as: 'We need a validation process with different health outcomes', 'We need an automation process', 'This is a good tool to look at mixtures', 'We need to translate DM results to epi [epidemiology] language' (different team members, Annual Meeting 4, Minutes).

Although this was the official end of the project, one of the more comprehensive propositions for hypotheses prioritization, which was introduced in the meeting, was followed through by several team members. They further developed a validation approach by integrating DM, GIS, and statistics into an integrative framework that helped the validation of the DM findings required for the generation of five robust hypotheses [37]. These hypotheses were reviewed and approved by the whole team, and the joint team publication describing these results is underway [38].

\subsection{Research Outcomes and Knowledge Translation}

Over the five operational years of the project, the outcomes included development of a new algorithm; creation of an interactive visualization tool to visualize data mining results; identification of an initial list of potential hypotheses and a secondary list of robust hypotheses linking specific chemical pollutants mixtures with $\mathrm{ABO}$. Additionally, the project had other 'side outcomes' such as new classification methods in DM [39], ABO and industrial pollutants maps [40], description of $A B O$ and related risk factors' prevalence [41], testing the usefulness of existing publicly available data, learning about the collaborative process, and training a new generation of interdisciplinary researchers in environmental health.

The project's framework contemplated, from the very start, knowledge translation and exchange as part of the research process. Thus, sharing the gained knowledge to contribute to research practice and policy, that may advance and optimize children's health, was central to the project. Many discussions and planning sessions took place during the project's process on what this knowledge translation exchange would look like considering the complexity of communicating about air pollution [42]. This included what the impact of the research could be, who the users would be, how and what to share, and how to best connect with stakeholders. As the KT plan developed along the progression of the project, the resulting knowledge exchange activities included different forms of engagement. The team initiated targeted and interactive activities with varying stakeholders with clinical, research and policy interests. Engagement activities included hands-on workshops, presentations, and webinars to our team members' organizations (medical departments and agencies) and other stakeholders' organizations. Additionally, the team engaged in traditional dissemination of results, like scientific publications and presentations in local, national and international conferences. Some KT activities are still in progress and members of the team continue to collaborate on different spheres.

\subsection{Facilitators and Challenges}

A complex context and the research scope challenged the DoMiNO project. It involved discovery research in a poorly explored territory, aiming to identify associations between $\mathrm{ABO}$ and mixtures of pollutants, some of which have unknown toxic potential. Challenges also included the development 
and application of a new methodology for identifying mixtures, working with data limitations such as lack of details or need for aggregation, and the constant expectation of proving causality.

However, the collaborative and interdisciplinary nature of the project and the team's commitment provided the conditions to develop and support such an innovative project. As was noted in one of the field notes: "It was very helpful to have team members with different familiarities (a data analyst, a medical expert, people familiar with the databases and what they do and do not offer, familiar with the chemical release reporting systems). Also, helpful to have a group who uses a variety of research techniques. The discussion would not have gone anywhere without the combined expertise and diversity of the group" (Field Notes, Meeting 3).

Moreover, the inclusion of data providers/custodians and NGO representative as team members supported all the phases of the research, including the knowledge translation. The diverse and comprehensive input from all members enabled the progression of the project, which would not have been possible otherwise; thus, the inclusion of all team members in the different activities of the project was imperative. It was an iterative process of learning and production, collectively and individually at times (e.g., only the data miners could develop the algorithm). Hence, the DM process could not have progressed into developing a meaningful algorithm without understanding the different considerations imposed by the context and why these mattered. Moreover, DM findings could not have been interpreted and validated without the assistance of the rest of the team.

Different channels of communication facilitated rapport, dialogue, engagement, participation and learning to support the ongoing collaboration. Among those, face-to-face meetings were the most efficient manners of communication, which included frequent small/sub team meetings and four annual two-day meetings for the whole team. Those interdisciplinary sessions and interactions promoted continuous learning and participation of different perspectives and at different times and were essential for progression and development. Annual full team meetings were designed by the principal investigators, research coordinator, and the meetings facilitator to respond to project needs. Planning of format and content were based on consultation and feedback received from the team: the steering committee, previous meeting evaluations, webinars, small /sub-team meetings, individual discussions. Annual face-to-face meetings usually involved formal and informal sessions, presentations and progress updates, interactive workshops designed for brainstorming on results, methods, challenges, interpretations, improvements, and future steps in large forum discussions and smaller groups. The team also engaged in evaluation surveys and reflective sessions, discussing the collaborative process to identify strengths and weaknesses as well as opportunities and challenges. Participation in the face-to-face meetings was almost always close to the maximum.

Webinars and newsletters were other channels for communication. Newsletters focused on providing updates on progress, outcomes, logistics, short-term plans, and summaries of team activities and decisions. Webinars (online seminars) were professional platforms for deliberations on details on methods and interim research outcomes from all arms of the project, and an opportunity to discuss future steps. In most cases, approximately 15 (3/4 of the team) members joined the webinars. All webinars were recorded and shared on the DoMiNO website to benefit those who may have missed the sessions.

The project faced logistic challenges, such as having the right personnel to address all aspects of the research, and team members who had competing priorities and geographic distances. However, this partnership supported and grounded the research and steered the research towards exciting and meaningful outcomes, as well as dissemination and application in different domains.

Figure 2 illustrates the DoMiNO's project main milestones, the different elements that supported the promotion of the interdisciplinary and collaborative practice, and the contribution of the different disciplines during the years of operation. 


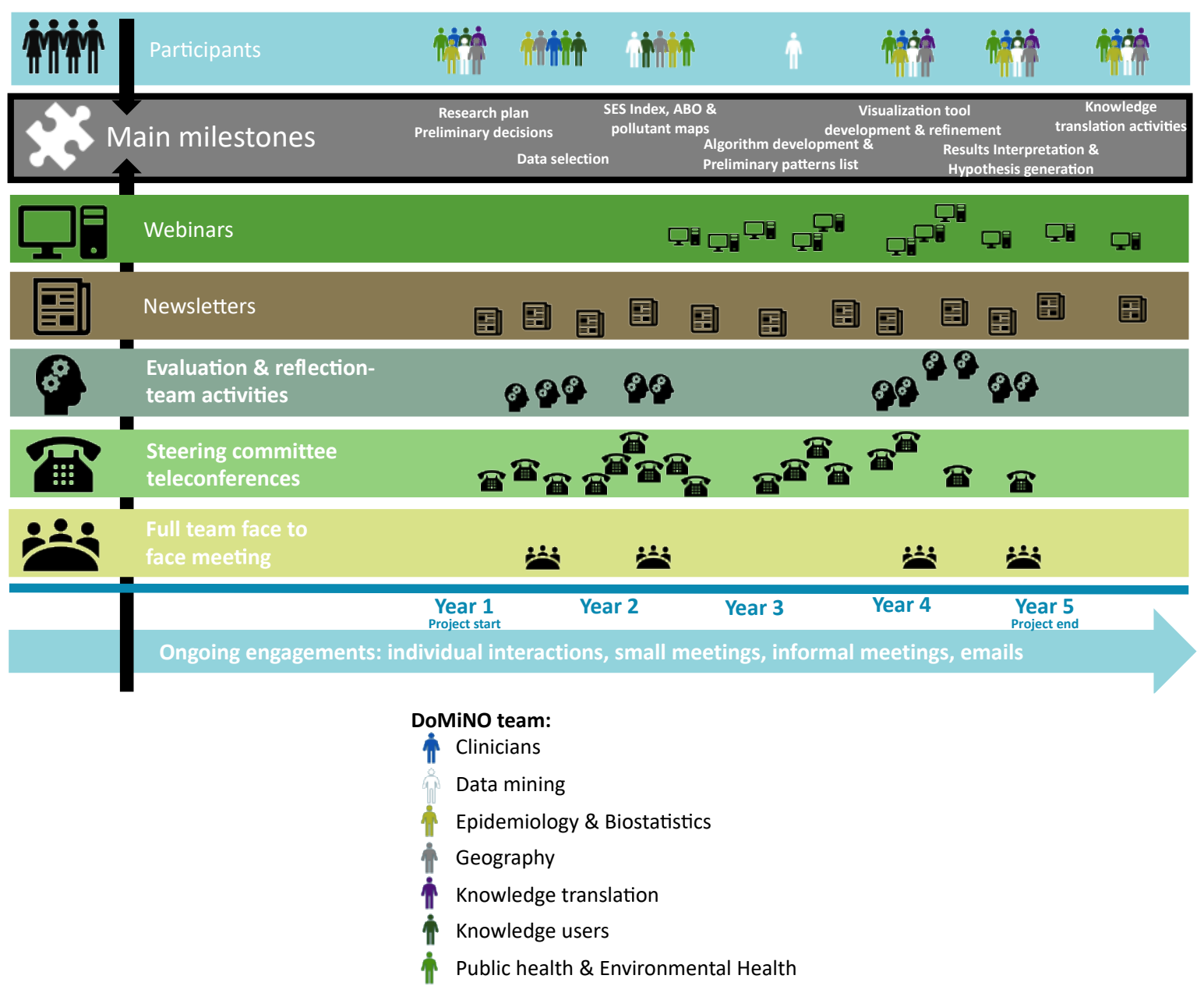

Figure 2. DoMiNO project milestones and the elements promoting collaborative practice.

\section{Discussion}

In an attempt to understand the environment and how it impacts the health of the people and the planet, complex research is required to capture all the participating elements and understand how they connect, e.g., exposure to multi-pollutants in the air impacting different systems [43,44]. New research approaches are required along with diverse disciplines, collaborating to support this type of research as the scientific exploration moves to be more holistic and includes different aspects of the problem [45] (e.g., Exposome-Wide Association Study ExWAS [46], One Health [47]). Wild (2014), called for interdisciplinary research of the exposome, a collaboration across disciplines that use different paradigms, tools, and even language [2]. Dagnino, (2018) further emphasizes the significance of the collaboration of epidemiologists and statisticians with other experts to ensure proper study design, methodologies and analysis in exposome research, and provide examples of projects and centers devoted to the research of the exposome [48]. Thus, the DoMiNO project described above is an example of how a collaborative and interdisciplinary approach, including an array of specialists and expertise, can contribute to a novel research approach to address this complex context of the human exposome.

In a previous exploration of the literature on collaborative research in the EH context [49], we identified several approaches embracing interdisciplinary research in collaboration with knowledge users or stakeholders; among them are transdisciplinary research and community-based participatory research. Additionally, we identified key components of the collaborative research process that negatively or positively impact the collaborative process: allocating time and resources, addressing disciplinary and sectoral issues, building relationships, ensuring representation, embedding 
participation in the research, supporting ongoing collaboration, and developing knowledge translation (KT) and exchange. The literature review findings and those obtained from the DoMiNO collaborative process experience highlight several aspects that are of significance to interdisciplinary and collaborative research projects.

The interdisciplinary research process requires sufficient time and efforts to enable the building and maintenance of the collaborative process in order to optimize the partnership and achieve goals. Although it may seem at times that interdisciplinarity can create obstacles for progression, it actually pushes the work forward in a way that benefits the project to be more relevant and useable $[50,51]$. We have learned that collaboration is an evolving process, which starts from planning and writing the proposal and goes on to the next phases, in which relationship among team members evolve and strengthen over time, through formal and informal activities. The research progresses thanks to the integration of different perspectives, methods and experiences [52,53], and the team's commitment.

The interdisciplinary and stakeholder engagement process can only occur in a supportive environment that promotes learning and sharing ideas. Learning is especially essential, considering that members have different backgrounds, perspectives, and concepts. In order for the team to achieve its goal, it needs to build bridges to guarantee the progression of the research by learning, thinking, and employing different methods; and harmonizing discipline-specific terms or word meaning. The team needs to embrace different epistemologies, theories, and methods; challenge their own beliefs; and engage in reflexivity and self-awareness of one's own epistemology bias as part of the research process and interpretation of results [19]. Moreover, this type of research requires a team to think in 'discovery mode' to generate hypotheses; where logic, rigor and objectivity are insufficient at times and also ask for creativity and intuition [54]. Times for disagreement and breakdown of epistemologies may happen [55]. The integration, interpretation, assessment, and agreement on results is a difficult test and challenge for interdisciplinary practice. Different measures were suggested to overcome those challenges and facilitate best practices such as evaluation, reflection, and deliberations [49,52,55-58].

Furthermore, supporting the process of collaboration may help in overcoming discipline-related challenges as described above, as well as technical challenges due to team members' geographical distances $[59,60]$. Facilitating different communication channels can address different needs and availabilities. Evaluation and reflection can support the collaborative process as well [58]. It enables rapport and can help identify different needs of the collaborative process such as modifications to support systems employed to inform the process and to support learning and capacity building. In order to optimize future collaborative initiatives, research teams may want to consider including a specialist to support the collaborative aspects of the research, including formative evaluation $[61,62]$. Another approach would be to promote training in interdisciplinary and collaborative research for those involved $[2,19]$.

The case described here provided insights into the collaborative process within the complex context of EH research from real-life experience. It highlights not only the need for innovative research approach and the participation of an array of specialists working together to promote a comprehensive understanding of the exposome and its impact on human health, but also the process of establishing and maintaining these types of partnerships supportive of building research capacity and knowledge translation, in this evolving area of research.

Those engaged in collaborative research would probably find some similarities between this case and those emerging from their own experiences. Research teams would often have diverse expertise participating in their endeavors. However, we do not often spend time thinking about what aspects optimize research partnership practice. While we move forward with more complex research to explore the environmental impact, stories like the one presented here provide insights on the kind of encounters teams may face in light of the complexity of both the research itself and the collaborative process, and how to overcome those. 
Interdisciplinary experiences provide interesting new research outcomes, but are not exempt from challenges as the ones discussed above. Team members and leaders need to embrace a collaborative culture, acknowledge the challenges, and address them in their research process.

Building a team requires the investment of time towards building relationship and trust, building bridges between disciplines, and supporting an inclusive learning environment to help strengthen a successful collaborative project. Nonetheless, it is the team's commitment of both management and members to the collaborative process that makes the difference.

This case represents an example of a collaborative process in the complex context of the research of the exposome and is part of our ongoing exploration to understand the essential components and mechanisms necessary for collaborative teams' growth and performance. Future research should continue and promote more opportunities to learn from real-life stories in order to improve interdisciplinary collaborative practice.

Author Contributions: Conceptualization, O.W., O.R.Z., and A.R.O.V.; methodology, analysis, writing-original draft preparation, O.W.; writing — review and editing, O.W., O.R.Z. and A.R.O.V.; supervision, A.R.O.V.; project administration, A.R.O.V.; funding acquisition, O.W., O.R.Z., A.R.O.V.; resources, DoMiNO Project team.

Funding: This research was funded by CIHR/NSERC Collaborative Health Research Program (2013-2108), grant number (FRN)127789. O.W. was partially supported by the Women and Children's Health Research Institute (WCHRI) Student Scholarship (2015-2017).

Acknowledgments: We would like to acknowledge the participation and commitment of all the DoMiNO team members: Khalid Aziz, Nancy Aelicks, Colin Bellinger, Irena Buka, Sue Chandra, Susan Crawford, Paul Demers, Anders Erickson, Perry Hystad, M. Shazan M. Jabbar, Manoj Kumar, Kendra Malainey, Charlene C. Nielsen, Alvaro R. Osornio-Vargas, Erica Phipps, Jesus A. Serrano-Lomelin, Prakesh Shah, Dave Stieb, Paul J. Villeneuve, Osnat Wine, Yan Yuan, Osmar Zaiane. We would like to acknowledge the contribution of Sarah Bowen to the development of the collaborative framework design for the DoMiNO project. Additionally, we thank Kathy Kovacs Burns, Jude Spiers and Michael van Manen for their continuous advice.

Conflicts of Interest: The authors declare no conflict of interest. The funders had no role in the design of the study; in the collection, analyses, or interpretation of data; in the writing of the manuscript, or in the decision to publish the results.

\section{References}

1. World Health Organization Air Pollution and Child Health: Prescribing Clean Air. Available online: http: / /apps.who.int/iris/bitstream/handle/10665/275545/WHO-CED-PHE-18.01-eng.pdf?ua=1 (accessed on 11 December 2018).

2. Wild, C.P. The exposome: From concept to utility. Int. J. Epidemiol. 2012, 41, 24-32. [CrossRef] [PubMed]

3. Heaman, M.; Kingston, D.; Chalmers, B.; Sauve, R.; Lee, L.; Young, D. Risk factors for preterm birth and small-for-gestational-age births among canadian women. Paediatr. Perinat. Epidemiol. 2013, 27, 54-61. [CrossRef]

4. Kramer, M.S. The epidemiology of adverse pregnancy outcomes: An overview. J. Nutr. 2003, 133 (Suppl. 2), 1592S-1596S. [CrossRef]

5. World Health Organization. Preterm Birth. Available online: http://www.who.int/news-room/fact-sheets/ detail/preterm-birth (accessed on 11 December 2018).

6. Blencowe, H.; Cousens, S.; Chou, D.; Oestergaard, M.; Say, L.; Moller, A.B.; Kinney, M.; Lawn, J. Born Too Soon: The global epidemiology of 15 million preterm births. Reprod. Health 2013, 10 (Suppl. 1), S2. [CrossRef] [PubMed]

7. Kim, D.; Saada, A. The social determinants of infant mortality and birth outcomes in western developed nations: A cross-country systematic review. Int. J. Environ. Res. Public Health 2013, 10, 2296-2335. [CrossRef] [PubMed]

8. Shah, P.S.; Balkhair, T. Air pollution and birth outcomes: A systematic review. Environ. Int. 2011, 37, 498-516. [CrossRef]

9. Stieb, D.M.; Chen, L.; Eshoul, M.; Judek, S. Ambient air pollution, birth weight and preterm birth: A systematic review and meta-analysis. Environ. Res. 2012, 117, 100-111. [CrossRef] [PubMed]

10. Buka, I.; Koranteng, S.; Osornio Vargas, A.R. Trends in Childhood Cancer Incidence: Review of Environmental Linkages. Pediatr. Clin. N. Am. 2007, 54, 177-203. [CrossRef] 
11. Wine, O.; Hackett, C.; Campbell, S.; Cabrera-Rivera, O.; Buka, I.; Zaiane, O.; DeVito, S.C.; Osornio-Vargas, A. Using pollutant release and transfer register data in human health research: A scoping review. Environ. Rev. 2014, 22, 51-65. [CrossRef]

12. Kortenkamp, A.; Faust, M.; Scholze, M.; Backhaus, T. Low-level exposure to multiple chemicals: Reason for human health concerns? Environ. Health Perspect. 2007, 115 (Suppl. 1), 106-114. [CrossRef]

13. Heys, K.A.; Shore, R.F.; Pereira, M.G.; Jones, K.C.; Martin, F.L. Risk assessment of environmental mixture effects. RSC Adv. 2016, 6, 47844-47857. [CrossRef]

14. Norton, S.M.; Huyn, P.; Hastings, C.A.; Heller, J.C. Data mining of spectroscopic data for biomarker discovery. Curr. Opin. Drug Discov. Dev. 2001, 4, 325-331.

15. Obenshain, M.K. Application of Data Mining Techniques to Healthcare Data. Infect. Control Hosp. Epidemiol. 2004, 25, 690-695. [CrossRef]

16. Bailey-Kellogg, C.; Ramakrishnan, N.; Marathe, M.V. Spatial data mining to support pandemic preparedness. ACM SIGKDD Explor. Newsl. 2006, 8, 80-82. [CrossRef]

17. Bellinger, C.; Mohomed Jabbar, M.S.; Zaïane, O.; Osornio-Vargas, A. A systematic review of data mining and machine learning for air pollution epidemiology. BMC Public Health 2017, 17, 907. [CrossRef]

18. Van De Ven, A.H.; Johnson, P.E. Knowledge for theory and practice. Acad. Manag. 2014, 31, $802-821$. [CrossRef]

19. Repko, A.F.; Szostak, R. Interdisciplinary Research: Process and Theory, 3rd ed.; Sage Publications, Inc.: Los Angeles, CA, USA, 2017.

20. Fazey, I.; Bunse, L.; Msika, J.; Pinke, M.; Preedy, K.; Evely, A.C.; Lambert, E.; Hastings, E.; Morris, S.; Reed, M.S. Evaluating knowledge exchange in interdisciplinary and multi-stakeholder research. Glob. Environ. Chang. 2014, 25, 204-220. [CrossRef]

21. Briggs, D. A framework for integrated environmental health impact assessment of systemic risks. Environ. Health 2008, 7, 61. [CrossRef]

22. Newell, W.H. A Theory of Interdisciplinary Studies. Issues Integr. Stud. 2001, 19, 1-25.

23. Committee on Facilitating Interdisciplinary Research. Facilitating Interdisciplinary Research; National Academic Press: Washington, DC, USA, 2005.

24. Gavidia, T.; Brune, M.-N.; McCarty, K.M.; Pronczuk, J.; Etzel, R.; Neira, M.; Carpenter, D.O.; Suk, W.A.; Arnold, R.G.; Ha, E.H.; et al. Children's environmental health-from knowledge to action. Lancet 2011, 377, 1134-1136. [CrossRef]

25. O’Brien, L.; Marzano, M.; White, R.M. "Participatory interdisciplinarity": Towards the integration of disciplinary diversity with stakeholder engagement for new models of knowledge production. Sci. Public Policy 2013, 40, 51-61. [CrossRef]

26. Briggs, D.J.; Sabel, C.E.; Lee, K. Uncertainty in epidemiology and health risk and impact assessment. Environ. Geochem. Health 2009, 31, 189-203. [CrossRef] [PubMed]

27. Osornio-Vargas, A.; Zaiane, O.; Wine, O. Domino Project: Data Mining and Newborn Outcomes Exploring Environmental Variables. In Proceedings of the 26th Annual Conference of the International Society for Environmental Epidemiology, Seattle, WA, USA, 24-28 August 2014; p. 2187.

28. Yin, R.K. Case Study Research: Design and Methods, 3rd ed.; Sage Publication: Thousand Oaks, CA, USA, 2003.

29. Stake, E.R. Qualitative case studies. In Handbook of Qualitative Research, 3rd ed.; Denzin, N.K., Lincoln, Y.S., Eds.; SAGE Publications: Thousand Oaks, CA, USA, 2005.

30. Stake, E.R. The Art of Case Study Research; SAGE Publications: Thousand Oaks, CA, USA, 1995.

31. Bowen, S.J.; Graham, I.D. From knowledge translation to engaged scholarship: Promoting research relevance and utilization. Arch. Phys. Med. Rehabil. 2013, 94, S3-S8. [CrossRef]

32. CIHR. More About Knowledge Translation at CIHR-CIHR. Available online: http://www.cihr-irsc.gc.ca/ e/39033.html (accessed on 11 December 2018).

33. Jabbar, M.S.M.; Zaiane, O.R.; Osornio-Vargas, A. Discovering Spatial Contrast and Common Sets with Statistically Significant Co-location Patterns. In Proceedings of the Symposium on Applied Computing (SAC '17), Marrakech, Morocco, 3-7 April 2017; pp. 796-803.

34. Chan, E.; Serrano, J.; Chen, L.; Stieb, D.M.; Jerrett, M.; Osornio-Vargas, A. Development of a Canadian socioeconomic status index for the study of health outcomes related to environmental pollution Biostatistics and methods. BMC Public Health 2015, 15, 714. [CrossRef] 
35. Bellinger, C.; Jabbar, M.S.M.; Hojjati, S.; Wine, O.; Nielsen, C.; Serrano Lomelin, J.; Zaiane, R.O.; Osornio Vargas, A.R. VizAR: An Interactive Framework for Co-Location Pattern Visualization and Exploration. Manuscript in Preparation. 2019.

36. Bellinger, C.; Jabbar, M.S.M.; Hojjati, S.; Zaiane, R.O.; Osornio Vargas, A.R.; DoMiNO team. Vizar: A software tool for epidemiological hypothesis generation with geo-spatial data mining. In Proceedings of the 5th Canadian National Perinatal meeting, Banff, AB, Canada, 14-17 February 2018.

37. Nielsen, C.; Serrano-Lomelin, J.; Jabbar, S.; Wine, O.; Bellinger, C.; Zaiane, O.; Osornio Vargas, A.R. Integrative Strategy for Finding Co-Location Patterns between Adverse Birth Outcomes and Industrial Air Pollution. The International Society for Environmental Epidemiology Conference Abstracts; Environmental Health Perpectives. Volume 2018, Issue 124.

38. Serrano-Lomelin, J.; Nielsen, C.C.; Jabbar, M.S.M.; Wine, O.; Bellinger, C.; Villeneuve, P.J.; Stieb, D.; Aelicks, N.; Aziz, K.; Irena Buka, I.; et al. Building robust hypotheses on associations of mixtures of industrial air pollutants with adverse birth outcomes. Manuscript in Preparation. 2019.

39. Li, J.; Zaiane, O.R. Associative Classification with Statistically Significant Positive and Negative Rules. In Proceedings of the 24th ACM International Conference on Information and Knowledge Management (CIKM), Melbourne, Australia, 19-23 October 2015; pp. 633-642.

40. Nielsen, C.C.; Amrhein, C.G.; Osornio-Vargas, A.R. Mapping outdoor habitat and abnormally small newborns to develop an ambient health hazard index. Int. J. Health Geogr. 2017, 16, 43. [CrossRef]

41. Serrano Lomelin, J.A. Profiling Industrial Air-Pollutant Mixtures and Their Associations with Preterm Birth and Small for Gestational Age in Alberta, Canada. Ph.D. Thesis, University of Alberta, Edmonton, AB, Canada, 2018.

42. Wartenberg, D. Some considerations for the communication of results of air pollution health effects tracking. Air Qual. Atmos. Heal. 2009, 2, 207-221. [CrossRef] [PubMed]

43. Dominici, F.; Peng, R.D.; Barr, C.D.; Bell, M.L. Protecting Human Health From Air Pollution. Epidemiology 2010, 21, 187-194. [CrossRef]

44. Mauderly, J.L.; Burnett, R.T.; Castillejos, M.; Özkaynak, H.; Samet, J.M.; Stieb, D.M.; Vedal, S.; Wyzga, R.E. Is the air pollution health research community prepared to support a multipollutant air quality management framework? Inhal. Toxicol. 2010, 22, 1-19. [CrossRef]

45. Ledford, H. Team Science. Nature 2015, 525, 308-311. [CrossRef]

46. Agier, L.; Basagaña, X.; Maitre, L.; Granum, B.; Bird, P.K.; Casas, M.; Oftedal, B.; Wright, J.; Andrusaityte, S.; De Castro, M.; et al. Early-life exposome and lung function in children in Europe: An analysis of data from the longitudinal, population-based HELIX cohort. Lancet Planet. Health 2019, 3, e81-e92. [CrossRef]

47. Conrad, P.A.; Meek, L.A.; Dumit, J. Operationalizing a One Health approach to global health challenges. Comp. Immunol. Microbiol. Infect. Dis. 2013, 36, 211-216. [CrossRef]

48. Dagnino, S. Unravelling the Exposome: Conclusions and Thoughts for the Future. In Unraveling the Exposome: A Practical View; Dagnino, S., Macherone, A., Eds.; Springer International Publishing: Cham, Switzerland, 2019; pp. 425-437. ISBN 978-3-319-89321-1.

49. Wine, O.; Ambrose, S.; Campbell, S.; Villeneuve, P.J.; Kovacs Burns, K.; Osornio Vargas, A. Key components of collaborative research in the context of environmental health: A scoping review. J. Res. Pract. 2017, 13, 2.

50. Campbell, C.A.; Lefroy, E.C.; Caddy-Retalic, S.; Bax, N.; Doherty, P.J.; Douglas, M.M.; Johnson, D.; Possingham, H.P.; Specht, A.; Tarte, D.; et al. Designing environmental research for impact. Sci. Total Environ. 2015, 534, 4-13. [CrossRef] [PubMed]

51. Reed, M.S. Stakeholder participation for environmental management: A literature review. Biol. Conserv. 2008, 141, 2417-2431. [CrossRef]

52. Podestá, G.P.; Natenzon, C.E.; Hidalgo, C.; Ruiz Toranzo, F. Interdisciplinary production of knowledge with participation of stakeholders: A case study of a collaborative project on climate variability, human decisions and agricultural ecosystems in the Argentine Pampas. Environ. Sci. Policy 2013, 26, 40-48. [CrossRef]

53. Annerstedt, M. Transdisciplinarity as an inference technique to achieve a better understanding in the health and environmental sciences. Int. J. Environ. Res. Public Health 2010, 7, 2692-2707. [CrossRef]

54. Wilcox, A.J.; Cortese, M.; Baravelli, C.M.; Skjaerven, R. When intuition invites the analytical mind to dance-The essential role of creativity in science. Epidemiology 2018, 29, 753-755. [CrossRef]

55. Mengis, J.; Nicolini, D.; Swan, J. Integrating knowledge in the face of epistemic uncertainty: Dialogically drawing distinctions. Manag. Learn. 2018, 49, 595-612. [CrossRef] 
56. Hovelynck, J.; Dewulf, A.; François, G.; Taillieu, T. Interdisciplinary knowledge integration through group model building: Recognizing dualities and triadizing the conversation. Environ. Sci. Policy 2010, 13, 582-591. [CrossRef]

57. Nancarrow, S.A.; Booth, A.; Ariss, S.; Smith, T.; Enderby, P.; Roots, A. Ten principles of good interdisciplinary team work. Hum. Resour. Health 2013, 11, 19. [CrossRef] [PubMed]

58. Roux, D.J.; Stirzaker, R.J.; Breen, C.M.; Lefroy, E.C.; Cresswell, H.P. Framework for participative reflection on the accomplishment of transdisciplinary research programs. Environ. Sci. Policy 2010, 13, 733-741. [CrossRef]

59. Stokols, D.; Misra, S.; Moser, R.P.; Hall, K.L.; Taylor, B.K. The Ecology of Team Science. Understanding Contextual Influences on Transdisciplinary Collaboration. Am. J. Prev. Med. 2008, 35, S96-S115. [CrossRef] [PubMed]

60. Rekers, J.V.; Hansen, T. Interdisciplinary research and geography: Overcoming barriers through proximity. Sci. Public Policy 2015, 42, 242-254. [CrossRef]

61. Ramirez-Andreotta, M.D.; Brusseau, M.L.; Artiola, J.F.; Maier, R.M.; Gandolfi, A.J. Environmental research translation: Enhancing interactions with communities at contaminated sites. Sci. Total Environ. 2014, 497-498, 651-664. [CrossRef] [PubMed]

62. Meadow, A.M.; Ferguson, D.B.; Guido, Z.; Horangic, A.; Owen, G.; Wall, T. Moving toward the Deliberate Coproduction of Climate Science Knowledge. Weather Clim. Soc. 2015, 7, 179-191. [CrossRef]

(c) 2019 by the authors. Licensee MDPI, Basel, Switzerland. This article is an open access article distributed under the terms and conditions of the Creative Commons Attribution (CC BY) license (http://creativecommons.org/licenses/by/4.0/). 